\title{
The Inhibitor-Sensitive Sites of Galactosyl Ceramide Galactosidase'
}

\author{
RAMESH C. ARORA, ${ }^{2}$ YUH-NAN LIN, AND NORMAN S. RADIN \\ Mental Health Research Institute, University of Michigan, \\ Ann Arbor, Michigan 48104 \\ Received November 17, 1972
}

\begin{abstract}
A preparation of galactosyl ceramide galactosidase from rat brain has been tested with potential inhibitors which resemble the enzyme's substrate. The amide made from 2-hydroxydodecanoic acid and DL-erythro-3-phenyl-2-amino-1,3-propanediol proved to be a fine inhibitor, acting noncompetitively. Removal of any of the three hydroxyl groups reduced the effectiveness, as did inversion of the C-3 carbon atom or addition of substituents on the benzene ring. $N$-Acetyl psychosine was an effective inhibitor of the mixed type while the longer homolog, $N$-decanoyl psychosine, was a competitive inhibitor as well as substrate for the enzyme. Lactosyl ceramide, the naturally occurring lipid, was a competitive inhibitor of modest efficacy. Galactonolactone was an excellent competitive inhibitor and $N$ - $(n$-hexyl) psychosine was an active inhibitor of the mixed type. It would appear from the above comparisons that the enzyme's active site binds only galactose-containing or galactose-resembling substances, while the secondary effector site binds a variety of substances which possess the central nitrogenous core region of cerebroside.
\end{abstract}

As part of an attempt to develop specific agents which could block single steps in myelin metabolism, we have synthesized compounds which resemble in structure the myelin component, galactosyl ceramide ("cerebroside"). The hydrolase which normally acts on this lipid, a $\beta$-galactosidase, is defective in the human genetic disorder, Krabbe's disease, and an inhibitor for this enzyme might allow us to generate a model disorder in rats which mimics the human dystrophy.

We have already described some synthetic substances which are effective inhibitors of the galactosidase (1). These compounds had a structure similar to that of ceramide (the product of galactosidase action) in which the 2-amino-1,3-propanediol structure was retained but the long alkenyl side chain of sphingosine was replaced by a benzene ring. The very long nonhydroxy fatty acids typical 03192

1 Supported by TISPHS Research Grant NS-

${ }^{2}$ Present address: Department of Biochemistry, The Chicago Medical School, Chicago, IL 60612. of brain cerebroside were most effectively replaced by an abnormally short acid, decanoic or dodecanoic acid. Comparison of isomers showed that the most active inhibitor had the erythro configuration characteristic of naturally occurring sphingosine, and deletion of either of the two hydroxyl groups on the lipoidal amine drastically reduced the inhibitory effect. Substitutions on the benzene ring also weakened the effect. Kinetic analysis of the inhibition somewhat unexpectedly showed the inhibition to be noncompetitive and the implication is therefore that the inhibitor acts on a relatively distant site rather than at the catalytic site of the galactosidase.

An amide with an even simpler structure, $N$-decanoyl 2-amino-2-methylpropanol, was found to be a fairly good stimulator of the galactosidase (2). It is not known if this substance acts at the same site as the inhibitor.

This paper reports the results of further attempts to delineate the sensitive sites on the enzyme and to search for compounds that might be more effective inhibitors. 


\section{MATERIALS AND METHODS}

Preparation of the inhibitors. The aromatic amines used have been described before (1). DL-2Hydroxy fatty acids were prepared by hydrolyzing the bromoacids with $\mathrm{KOH}$ in water-tetrahydrofuran $^{3}$ and the bromo acids were either prepared here $^{3}$ or purchased. 2-Bromodecanoic acid was obtained from K\&K Laboratories, Ine., Plainview, NY. Bromolauric, myristic, and palmitic acids were bought from Aldrich Chemical Co., Inc., Milwaukee, WI. Psychosine was prepared by hydrolysis of cerebroside with $\mathrm{KOH}$ in water-butanol $(3,4)$.

The 2-hydroxy fatty acids were converted to amides through the following sequence: acetylation, reaction with thionyl chloride, reaction with the amine, and alkaline methanolysis to remove the protective acetate group $(1,5)$. Some acids were acetylated with isopropenyl acetate (6), others with a modified version of the Fritz-Schenk procedure (7). In the latter, 1 mmole of fatty acid was dissolved in $1 \mathrm{ml}$ of the acetic anhydrideperchloric acid reagent and, after $10 \mathrm{~min}$, the ester was isolated by partition between water and chloroform. After several washings with water, the chloroform layer yielded the ester. Alkaline methanolysis was carried out with $0.07 \mathrm{M} \mathrm{NaOH}$ in chloroform-methanol 2:1 for $1 \mathrm{hr}$. The amide was then recovered by partitioning with $0.2 \mathrm{vol}$ of acetic acid-water 1:30, washing the lower layer with water, and removing the chloroform.

The hydroxy acid amides made from L-3-phenyl2-amino-1-propanol, after purification with a silica gel column, yielded single spots when examined by tlc with chloroform-methanol-acetic acid $88: 4: 8$. However, the amides made from DLerythro-3-phenyl-2-amino-3-propanol and DLerythro-3-phenyl-2-amino-1,3-propanediol yielded two, equally intense spots on tle plates. A similar phenomenon had been observed earlier with cerebrosides made from DL-2-hydroxylignoeeric acid, in which case we found the faster spot to be the unnatural compound, containing the L-hydroxy acid (5). A similar relationship has been observed with ceramides containing DL-hydroxy acids, the slower spot being the natural compound, D-hy-

${ }^{3}$ Arora and Radin, unpublished data.

${ }^{4}$ Abbreviations and nomenclature: tlc, thin layer chromatography (carried out with silica gel PF-254, EM Reagent). Sphingosine, as used here, is the D-erythro, natural isomer (sphingenine). Ceramide is fatty acyl sphingosine, an amide. Psychosine is 1-( $O$ - $\beta$-galactosyl $)$ sphingosine. Cerebroside is galactocerebroside, or galactosyl ceramide, or $N$-acyl psychosine. Cerebrosidase is the enzyme which hydrolytically cleaves the galactose from cerebroside. Solvent mixtures are $\mathrm{v} / \mathrm{v}$. droxy acid, D-amine (8, 16). However, unlike Karlsson and Pascher ( 8 ), we found the acetyl ester (the intermediate in the synthesis) to give only a single spot with cerebrosides, ceramides, and the aromatic amides. Possibly their faster spot was contaminating free fatty acid.

In the case of the aromatic amides, it is probable that the faster spot consists of the racemic mixture, $\mathbf{L}$-acid, D-amine and D-acid, L-amine and the lower spot is L-acid, L-amine with D-acid, Damine.

Amides of psychosine were made like those of the aromatic amines, except (in the case of the acetyl compound) that acetic anhydride was used instead of acetyl chloride. In these syntheses the nonpolar impurities were removed with a silica gel column by elution with chloroform-methanol 98:2 and the amides were eluted with chloroformmethanol 94:6. The tlc with silica gel and chloroform-methanol-water-ammonium hydroxide 48 : 14:1:1 revealed a single spot for each compound. Labeled $N$-decanoyl psychosine was made from $\left[1{ }^{14} \mathrm{C}\right]$-decanoic acid and diluted to a specific activity of $1100 \mathrm{cpm} / \mathrm{nmole}$. The purified cerebroside yielded one spot with tlc with chloroformmethanol-water 24:7:1 and counting of the spot and nearby tle regions indicated the radiopurity to be at least $94 \% . N$-(n-Hexyl)-O-glucosyl sphingosine was synthesized as previously described (9) and the galactosyl analogue was made similarly.

Cerebroside galactosidase assays. The previously described procedure was used (1). This involved use of a partially purified galactosidase preparation derived from $3 \mathrm{mg}$ of ruc brain, incubation with an emulsion of radioactive $N$-stearoyl psychosine (3), and determination of the amount of galactose released. A typical control incubation without enzyme yielded $122 \mathrm{cpm}$, corresponding to $0.15 \%$ of the amount of cerebroside in the incubation tube. The compound to be tested as an inhibitor was first deposited on the walls of the incubation tube by evaporation from solvent, generally at a level which yielded a concentration of 0.3 mM. After each run, which included control incubations without inhibitor, the degree of inhibition was calculated from the decrease in the number of cpm from the control samples.

\section{RESULTS}

Inhibition by aromatic 2-hydroxy acid amides. All the amides of nu-erythro-3-phenyl-2-amino-1,3-propanediol were found to be inhibitory (Table I). While there was little difference between compounds of differing chain length at $0.3 \mathrm{~mm}$ inhibitor concentration, the superiority of the dodecanoyl derivative was more clearly revealed at the 30 
TABLE I

Inhibition of Cerebrosidase by 2-Hydroxy Fatty Acid "Amides of PhinyliamoPROPANEDIOL

\begin{tabular}{ccccc}
\hline \multirow{2}{*}{$\begin{array}{c}\text { Fatty } \\
\text { acid } \\
\text { chain } \\
\text { length }\end{array}$} & \multicolumn{3}{c}{ Percentage inhibition } \\
\cline { 2 - 5 } & $\begin{array}{c}\text { L-threo } \\
\text { isomer }\end{array}$ & $\begin{array}{l}\text { D-threo } \\
\text { isomer }\end{array}$ & \multicolumn{2}{c}{$\begin{array}{c}\text { DL-erythro } \\
\text { isomer }\end{array}$} \\
\cline { 3 - 5 } & $300 \mu \mathrm{MM}$ & $300 \mu \mathrm{M}$ & $300 \mu \mathrm{M}$ & $30 \mu \mathrm{ML}$ \\
\hline 18 & 7 & & 60 & 26 \\
$\mathbf{1 6}$ & & & 54 & 31 \\
14 & & & 60 & 38 \\
12 & 37 & 31 & 69 & 44 \\
10 & 26 & & 67 & 29
\end{tabular}

$\mu \mathrm{M}$ level. In those cases where the threo isomers were tested, decreased effectiveness was observed.

The omission of either of the two hydroxyl groups on the aromatic amine, or the addition of a para substitution on the benzene ring lead to reduced inhibitory power (Table II). The $3-\mathrm{OH}$ group was not as important as the 1-OH group in producing inhibition.

Replacement of the benzene ring by an alkyl chain ( $N$-hydroxydodecanoyl D-sphingosine) aimost completely destroyed the inhibitory effect: $10 \%$ at $0.3 \mathrm{~mm}$ and $3 \%$ at $30 \mu \mathrm{M}$.

These findings agree well with the results with nonhydroxy acid amides. Apparently the best inhibitor contains an acid of about 12 carbon atoms, attached to an amine bearing the 1-hydroxy, 2-amino, 3-hydroxy, 3phenyl sequence. 'The presence of the DL-hydroxyl group on the fatty acid also enhances the effect; in the case of the decanoates, the unsubstituted acid produced $48 \%$ inhibition at $0.3 \mathrm{~mm}$ and the 2-hydroxy analogue produced $67 \%$ inhibition.

Nature of the inhibition by the propanediol amide. The most active inhibitor, hydroxydodecanoyl phenylaminopropanediol, was evaluated according to the Lineweaver-Burk method and found to be of the noncompetitive type (Fig. 1). While this was unexpected because of the marked similarity between the inhibitor and the product of enzyme action, a similar finding had been obtained with the analogous compound lacking the $\mathrm{OH}$ on the acyl chain (1). The $K_{i}$ calculated for the hydroxy inhibitor was $0.10 \mathrm{~mm}$, which
TABLE II

INHIBITION OF CeREBRosidase BY 2-HydROXYdodecanoyl Amides of Various Aromatic Amino Alcohols

\begin{tabular}{|c|c|c|c|c|c|}
\hline \multirow{2}{*}{$\begin{array}{c}\text { Aromatic } \\
\text { substi- } \\
\text { tution }\end{array}$} & \multirow[t]{2}{*}{$X$} & \multirow[t]{2}{*}{$Y$} & \multirow[t]{2}{*}{$\begin{array}{l}\text { Config- } \\
\text { uration }\end{array}$} & \multicolumn{2}{|c|}{$\%$ Inhibition } \\
\hline & & & & $300 \mu \mathrm{M}$ & $30 \mu \mathrm{Mr}$ \\
\hline $\mathrm{H}$ & $\mathrm{OH}$ & $\mathrm{H}$ & & 49 & 14 \\
\hline $\mathrm{H}$ & $\mathrm{H}$ & $\mathrm{OH}$ & DL-erythro & 16 & \\
\hline $\mathrm{H}$ & $\mathrm{OH}$ & $\mathrm{OH}$ & DL-erythro & 69 & 44 \\
\hline$p$-nitro & $\mathrm{OH}$ & $\mathrm{OH}$ & D-threo & 33 & \\
\hline$p$-nitro & $\mathrm{OH}$ & $\mathrm{OH}$ & L-threo & 31 & \\
\hline$p$-nitro & $\mathrm{OH}$ & $\mathrm{OH}$ & DL-eryythro & 35 & 21 \\
\hline$p$-phenyl & $\mathrm{OH}$ & $\mathrm{OH}$ & L-threo & 15 & \\
\hline
\end{tabular}

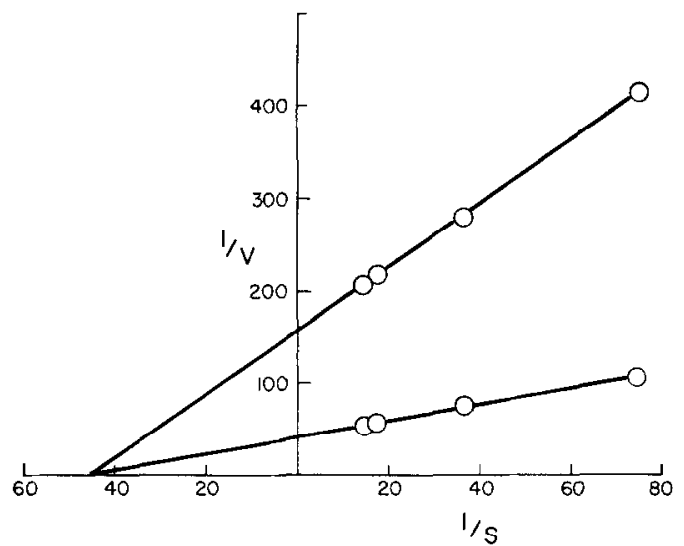

FIG. 1. Lineweaver-Burk plot of the galactocerebrosidase activity in a rat brain preparation, with and without $N$-hydroxydodecanoyl DLerythro-3-phenyl-2-amino-1,3-propanediol. The inhibitor (upper curve) was added at $0.3 \mathrm{~mm}$. The incubation tubes contained varying amounts of labeled stearoyl psychosine (expressed as $1 / \mathrm{mm}$ ) emulsified with Tween 20 and Myrj 59 in the weight ratios 1:20:5. The ordinate is expressed as 1/ $\mu$ moles cerebroside hydrolyzed in $3 \mathrm{hr}$.

can be compared with the value of $0.40 \mathrm{~mm}$ previously found with the nonhydroxy inhibitor.

Measurement of the inhibitory effect as a 
function of concentration of the hydroxy acid amide showed that maximal inhibition, about $82 \%$, was reached at concentrations greater than $0.6 \mathrm{~mm}$ (Fig. 2). The lack of a discontinuity in the curve (a sudden flattening off) indicates that solubility limitation was not the causc of the failure to attain higher levels of inhibition.

The time course of the inhibited and uninhibited hydrolytic reactions proceeded at a constant rate, indicating that no chemical reaction occurred between the inhibitor and the enzyme.

Inhibition by $N$-Acyl Psychosines. All the acylated psychosine compounds (which are actually galactocerebrosides with abnormally short fatty acids) proved to be inhibitory (Table III). The decanoyl and probably the hydroxydodecanoyl amides were the most effective. A kinetic analysis of the effect of acetyl psychosine showed (Fig. 3) that it acts like a mixed type inhibitor-partially competitive and partially noncompetitive. The double mode of action is reflected in the relationship between inhibitor concentration and inhibitory action (Fig. 4). Instead of leveling off, the curve continues to rise, evidently due to increasingly effective competition for the active enzyme site between the radioactive

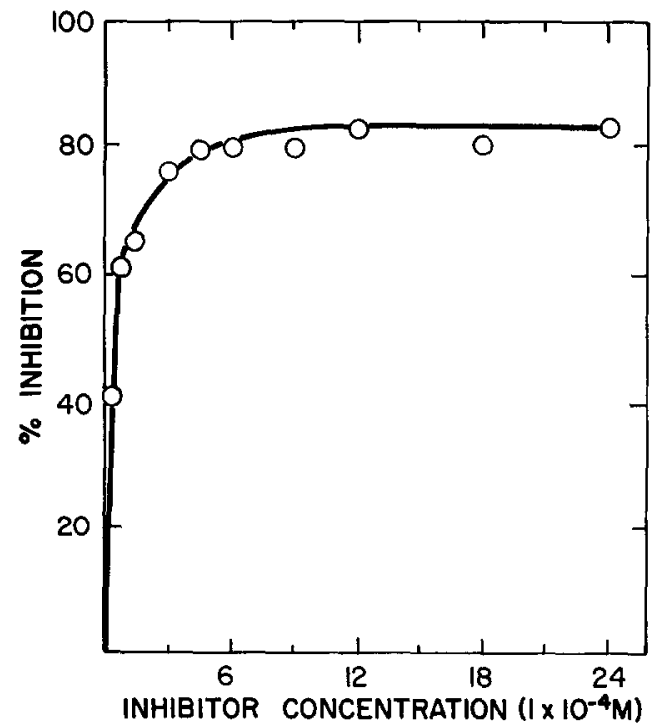

FIG. 2. Relationship between degree of inhibition and concentration of $N$-hydroxydodecanoyl DL-erythro-phenylaminopropanediol.
TABLE III

Inhibition of Cerebrosidase by Homologs of Cerebroside

\begin{tabular}{ccc}
\hline Fatty acid & \multicolumn{2}{c}{ Percentage inhibition } \\
\cline { 2 - 3 } & $\begin{array}{c}300 \mu \mathrm{M} \\
\text { cerebroside }\end{array}$ & $\begin{array}{c}30 \mu \mathrm{M} \\
\text { cerebroside }\end{array}$ \\
\hline $12: 0$ & 46 & 16 \\
$10: 0$ & 60 & 30 \\
$8: 0$ & 61 & \\
$6: 0$ & 62 & 20 \\
$2: 0$ & 57 & 13 \\
$2-\mathrm{OH} 12: 0$ & 66 & \\
$2-\mathrm{Br} 6: 0$ & 66 & 21 \\
\hline
\end{tabular}

cerebroside and the diminutive cerebroside. Even at the low concentration of $75 \mu \mathrm{M}$, the acetyl compound produced $31 \%$ inhibition.

Decanoyl psychosine, which resembles the nialural substrate more closely, was found to act as a competitive inhibitor. The $K_{i}$ for this interaction was about $86 \mu \mathrm{M}$, which can be compared with the $K_{m}$ observed with the natural substrate: $22 \mu \mathrm{M}$.

To test the possibility that the decanoyl psychosine was acting as a substrate, we incubated the enzyme preparation with the radiuactive inhibitor under the same assay conditions used for our usual substrate, stearoyl psychosine. Because of the difference in site of label, the incubation mixture had to be processed via a column separation (5). We found that $41 \%$ of the 10:0-cerebroside was converted to ceramide and that negligible free fatty acid was formed. The control incubation without enzyne yielded only $0.5 \%$ conversion (or contamination of the ceramide fraction). As our enzyme preparation hydrolyzes only about $30 \%$ of the 18:0cerebroside, it is evident that the shorter chain galactolipid is a better substrate and might be more useful in determining cerebrosidase activities.

Inhibition by lactosyl ceramide. When we first discovered the presence of an effector site on the cerebrosidase molecule, sensitive to noncompetitive inhibitors, we suggested that a naturally occurring ceramide derivative acts normally at that position, to controi the enzyme's activity (1). One candidate for this role is galactosyl glucosyl ceramide, an intermediate in ganglioside metabolism, 


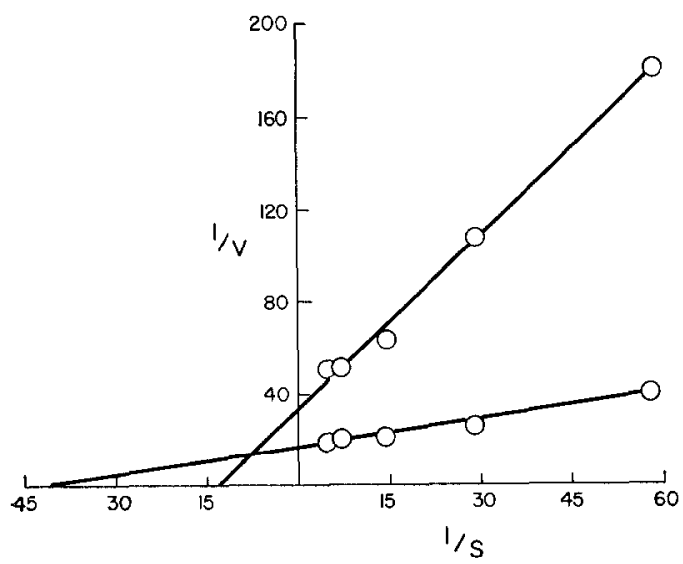

FIG. 3. Inhibitory effect of $N$-acetyl psychosine on galactocerebroside hydrolase. Units as in Fig. 1. The upper curve was derived from incubations containing $0.3 \mathrm{~mm}$ inhibitor.

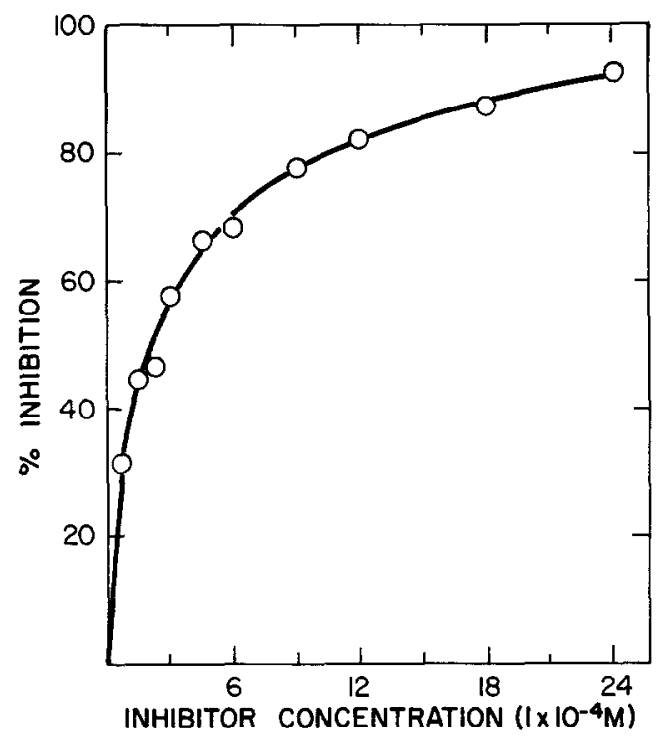

FIG. 4. Relationship between degree of inhibition and concentration of $N$-acetyl psychosine.

which occurs in tissues at low levels. We had found the natural compound (prepared by partial hydrolysis of gangliosides) to be a fairly good inhibitor (10). A test with $N$ stearoyl O-lactosyl DL-erythro-sphingosine (Miles Laboratories, Kankakee, IL) resulted in only $27 \%$ inhibition at $0.3 \mu \mathrm{M}$. However, it is possible that only the $\mathrm{D}$-isomer is the active form. A kinetic evaluation of the effect showed the DL-compound to be a competitive inhibitor with a $K_{i}$ of about 0.8 ma. Evi- dently the galactosyl moiety of this substance brings it to the active site of the enzyme, and it does not fit the proposed role of effector substance. However, there is the possibility that the high levels of lactosyl ceramide seen in certain disorders, as in lactosyl ceramidosis (11), could decrease cerebrosidase activity through its attraction to the cataly tic site.

This lipid has been found not to inhibit the intestinal glucosidase that acts on glucosyl ceramide (12).

Other inhibitors. Aldonolactones corresponding to specific glycosides act as competitive inhibitors of the corresponding glycosidases (13, 14). Galactonolactone had previously been shown to inhibit cerebrosidase as well, and gluconolactone was ineffective (10). We made a more detailed study, using gamma-galactonolactone equilibrated to a mixture of isomers, and found that it acts as a competitive inhibitor, the $K_{i}$ being about $38 \mu \mathrm{M}$ (Fig. 5).

It seemed possible that the lactone might combine chemically with the enzyme, possibly forming an amide or ester linkage with an amine or hydroxyl group near the active site. However the time course of the inhibitory effect was found to be linear over $3 \mathrm{hr}$, the first time point being measured at $30 \mathrm{~min}$. Thus it would appear that the lactone simply binds through nonchemical forces at the galactose-binding region.

It is of interest that galactonic acid is a normal metabolic product formed from galactose (15). While the free acid may not be an inhibitor for galactosidases, it may be converted to the lactone in lysosomes if there is a region of low $\mathrm{pH}$ in these particles.

We also tested some compounds related to the antibiotic, chloromycetin. These were the amides of dichloroacetic acid and $p$-substituted derivatives of 3-phenyl-2-amino1,3-propanediol. The thiomethyl ether of the DL-threo compound, the methyl sulfone of the DL-erythro compound, and the $n$-butyl sulfone of the Du-threo compound all proved to be almost inactive at $0.3 \mathrm{~mm}$.

The reduced, short-chain cerebrosides were rather inhibitory. At $0.3 \mathrm{~mm}, N$-hexyl glucosyl sphingosine caused about $36 \%$ inhibition and $N$-hexyl galactosyl sphingosine caused about $68 \%$ inhibition. When evalu- 


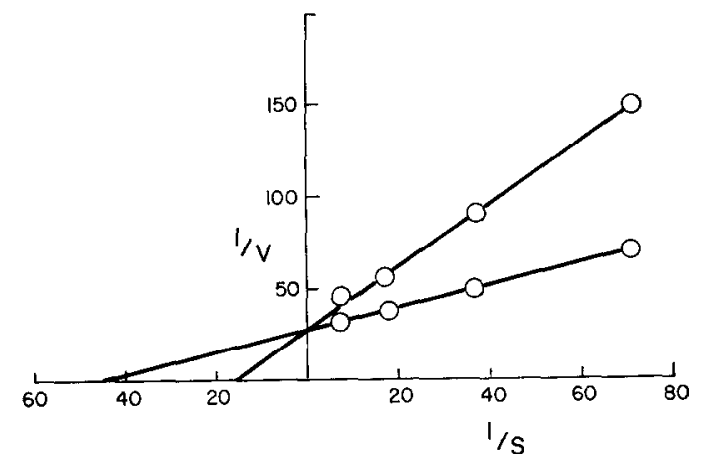

FIG. 5. Lineweaver-Burk plot of enzyme activity vs concentration of substrate. Upper curve, obtained with $0.5 \mathrm{~mm}$ galactonolactone. Units as in Fig. 1.

ated by the Lineweaver-Burk plot, the glucosyl compound proved to be a noncompetitive inhibitor with $K_{i}=0.30 \mathrm{~mm}$, while the galactosyl compound proved to be a mixed type inhibitor with $K_{i}=0.15 \mathrm{~mm}$. When tested with the spleen enzyme which hydrolyzes glucosyl ceramide, the glucosyl compound acted as a highly active competitive inhibitor with $K_{i}=0.33 \mu \mathrm{M}(9)$. Galactosyl sphingosine, without an alkyl group, produced only $13 \%$ inhibition at $0.3 \mathrm{~mm}$.

\section{DISCUSSION}

It appears from this and our previous study (1) that rat brain cerebroside galactosidase possesses two sites which can bind interfering substances. Some inhibitors bind exclusively to the secondary, noncompetive site (the aromatic amides resembling ceramide and the $N$-alkyi glucosyl sphingosine), while others bind to the secondary and catalytic sites (acetyl psychosine and $N$-hexyl psychosine). Only the compound most closely resembling galactose, galactonolactone, and the galactoside with the least lipoidal aglycone, lactosyl ceramide, binds solely to the cataly tic site.

Judging by the above comparisons, it would appear that the catalytic site binds only galactose-containing or galactose-resembling compounds. Evidently the design of better inhibitors for the active site should aim at glycosides with lipoidal aglycones containing galactose or a closely related sugar. However such compounds, such as our decanoyl psychosine, run the risk of being substrates for the enzyme.

Perhaps a better approach would be the synthesis of substances which bind to the secondary enzyme site (or sites). It is clear that this enzyme region has a strong influence on the catalytic efficiency of the cerebrosidase.

The high specificity of the secondary binding site is striking. It is sensitive to the optical configuration of the carbon atom bearing the amide group, and to the presence of three different hydroxyl groups, as well as to the presence of substituents on the benzene ring. The best effects are obtained with compounds which closely resemble the polar segment of hydroxy ceramide. An explanation for this phenomenon can be based on current genetic theory of protein evolution (17). Early in animal history there may have been a genetic modification which produced a partial duplication of the gene coding for cerebrosidase. The new gene then produced an elongated molecule of cerebrosidase containing a partial replication of the amino acid sequence containing the active site. Subsequent mutations may have then modified the second active site to its present. state: no longer catalytically active but still able to bind substances resembling the natural substrate. Several examples of proteins containing partial or complete duplication are now known (17).

\section{ACKNOWLEDGMENTS}

Mrs. Inez Mason and Carol Seidl assisted in the accomplishment of these experiments. We thank Dr. R. A. Cutler of Sterling-Winthrop Research Institute for furnishing the sulfur-containing amides. The phenylaminopropanediols were gifts from Parke, Davis \& Co. Dr. Kenneth Rabinowitz prepared the $N$-hexyl derivatives. We thank Dr. Park Gerald, of The Children's Hospital Medical Center, Boston for the suggestion on the genetic origin of the second site in cerebrosidase.

\section{REFERENCES}

1. Arora, R. C., and Radin, N. S. (1972) J. Lipid Res. 13, 86-91.

2. Arora, R. C., and Radin, N. S (1972) Lipids 7, 56-59.

3. RAdiN, N. S. (1972) in Methods of Enzymology (Ginsburg, V., ed.), Vol. 28, p. 301, Academic Press, New York. 
4. Taketomi, T., and Yamakawa, T. (1963), T. (1963) J. Biochem. 54, 444-451.

5. HajRa, A. K., Bowen, D. M., Kisuimoto, Y., And Radin, N. S. (1966) J. Lipid Res. 7, 379-386.

6. Kishimotto, Y., and Radin, N. S. (1963) $J$. Lipid Res. 4, 130-138.

7. Fritz, J. S., ANd Schenk, G. H. (1959) Anal. Chem. 31, 1808-1812.

8. Karlsson, K.-A., and Pascher, I. (1971) $J$. Lipid Res. 12, 466-472.

9. Erickson, J. S., and Radin, N. S. (1973) J. Lipid Res., in press.

10. Bowen, D. M., and Radin, N. S. (1968) Biochim. Biophys. Acta 152, 599-610.

11. Dawson, G. (1972) J. Lipid Res. 13, 207-219.
12. Brady, R. O., Gal, A. E., Kanfer, J. N., and Bradley, R. M. (1965) J. Biol. Chem. 240, 3766-3770.

13. Levvy, G. A., Hay, A. J., and Conchie, J. (1963) Biochem. J. 91, 378-384.

14. Heyworth, R., and Walker, P. G. (1962) Biochem. J. 83, 331-335.

15. Bergren, W. R., NG, W. G., Donneld, G. N., and Markey, S. P. (1972) Science 176, 683684.

16. Ullman, M. D., and Radin, N. S. (1972) Arch. Biochem. Biophys. 152, 767-777.

17. Dayhoff, M. O., And Eck, R. V. (1968) Atlas of Protein Sequence and Structure 1967-68, pp. 15-31, Nat. Biomed. Res. Found., Silver Spring, Md. 